\title{
Pancreatitis Aguda Recidivante por Ascaris Lumbricoides
}

\author{
Arancha Albal García ${ }^{a}$, Juan Carlos Segura Luque ${ }^{\mathrm{b}}$, Santiago Gómez Ramíreza ,

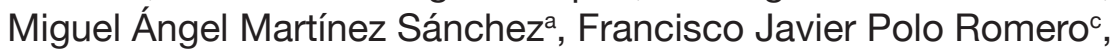 \\ Julio Manuel Moreno Salcedoc ${ }^{c}$, José Luis Beato Pérez ${ }^{c}$
}

\begin{abstract}
${ }^{a}$ Residente de Medicina Familiar y Comunitaria. Unidad Docente de Albacete-Hellín.

b Servicio de Medicina Interna. Complejo Hospitalario Universitario de Albacete.

c Servicio de Medicina Interna. Hospital de Hellín.
\end{abstract}

Correspondencia: Santiago Gómez Ramírez. Hospital de Hellín, c/ Juan Ramón Jiménez $\mathrm{s} / \mathrm{n}$, Hellín (Albacete).

e-mail: santiresi@hotmail.com

Recibido el 1 de agosto de 2007.

Aceptado para su publicación el 14 de noviembre de 2007.

\section{RESUMEN}

La ascariasis es la parasitosis más frecuente de todas las helmintiasis en humanos. Los efectos patológicos producidos por los áscaris en el hombre se presentan en lugares diversos, de acuerdo con la localización de sus distintas formas evolutivas. La ascariasis biliar en una de las complicaciones más severas. Presentamos un caso de pancreatitis aguda producida por infestación por Áscaris.

Palabras clave. Pancreatitis aguda, áscaris lumbricoides.

\section{ABSTRACT}

Acute necrotising pancreatitis by ascaris lumbricoides

Ascariasis is the commonest parasitosis of all human helminths. The pathological effects that ascaris produces in man manifest in different locations, in accordance with the location of its different evolutionary forms. Biliary ascaris is one of the severest complications. We present a case of acute pancreatitis produced by Ascaris infestation.

Key words. Pancreatitis acute, ascaris lumbricoides.

\section{INTRODUCCIÓN}

La ascariasis es la parasitosis más frecuente y cosmopolita de todas las helmintiasis en humanos y abunda en las regiones donde la pobreza, las condiciones de vivienda en hacinamientos y la mala sanidad ambiental son comunes. Los efectos patológicos producidos por los áscaris en el hombre se presentan en lugares diversos, de acuerdo con la localización de sus distintas formas evolutivas. La ascariasis biliar en una de las complicaciones más severas. Presentamos un caso de pancreatitis aguda producida por infestación por Áscaris.

\section{OBSERVACIONES CLÍNICAS}

Se trata de un varón de 21 años procedente de Ecuador y residente en España desde el año 2001. Refería episodios recurrentes de dolor abdominal, autolimitados y de leve intensidad y años de evolución. No relataba hábito enólico. Ingresó en dos ocasiones, en los últimos cuatro meses, por episodios clínicos, analíticos y de imagen compatibles con pancreatitis aguda alitiásicas e idiopáticas, resueltas con tratamiento conservador. Reingresó por nuevo episodio de dolor abdominal, fiebre y elevación de amilasa sanguínea. La ecografía y la tomografía axial computerizada (TAC) no mostraron alteraciones patológicas. La colangio-resonancia reveló una alteración de señal lineal en el conducto hepático izquierdo y común (figura 1). Se realizó una gastroscopia donde se observaron en estómago y duodeno múltiples parásitos de hasta $15 \mathrm{~cm}$ de longitud (figura 2). Tras la extirpación endoscópica y tratamiento con Mebendazol, el paciente evolucionó favorablemente y sin presentar, en controles posteriores, episodios similares. 


\section{DISCUSIÓN}

La migración de los parásitos intestinales al árbol biliar puede producir cuadros de obstrucción biliar, colangitis ó pancreatitis. Las manifestaciones clínicas varían en severidad según el número de parásitos o si permanecen en los conductos o regresan al intestino, predominando el dolor abdominal, náuseas y vómitos. Las pruebas de imagen abdominal son útiles en el diagnóstico de sospecha, siendo infrecuente recurrir a la cirugía. El tratamiento con Mebendazol, junto a la extracción endoscópica, es curativo en el $90 \%$ de los casos, reservándose la cirugía si existe sepsis incontrolada, colangitis supurada o fallo en el tratamiento médico.

La mortalidad es del 3\% en las áreas endémicas con tratamiento específico, sin embargo, en sitios donde es infrecuente pueden producirse fatales consecuencias si se demora su diagnóstico. La pancreatitis aguda por Ascaris lumbricoides es extremadamente rara en Europa. El diagnóstico es difícil por el bajo índice de sospecha en nuestra área. La ascariasis debe ser recordada como una causa infrecuente de pancreatitis aguda en los países occidentales.

\section{BIBLIOGRAFÍA}

1. Larrubia JR, Ladro JM, Mendoza JL, Morillas JD, Díaz-Rubio $M$. The role of sonography in the early diagnosis of biliopancreatic Ascaris infestation. J Clin Gastroenterol 1996; 22(1):48-50.

2. Sandouk F. Pancreatic-billiary ascariasis: experience of 300 cases. Am J Gastroenterol 1997; 92(12): 2264-7.

3. Botenbe N. A rare cause of billiary pain in Belgium. Acta Gastroenterol Belg 1999; 62 (4): 443-5.

4. Mackrell P. Pancreatitis secondary to Áscaris lumbricoides infestation. Surgery 2001; 129(4):511-2.
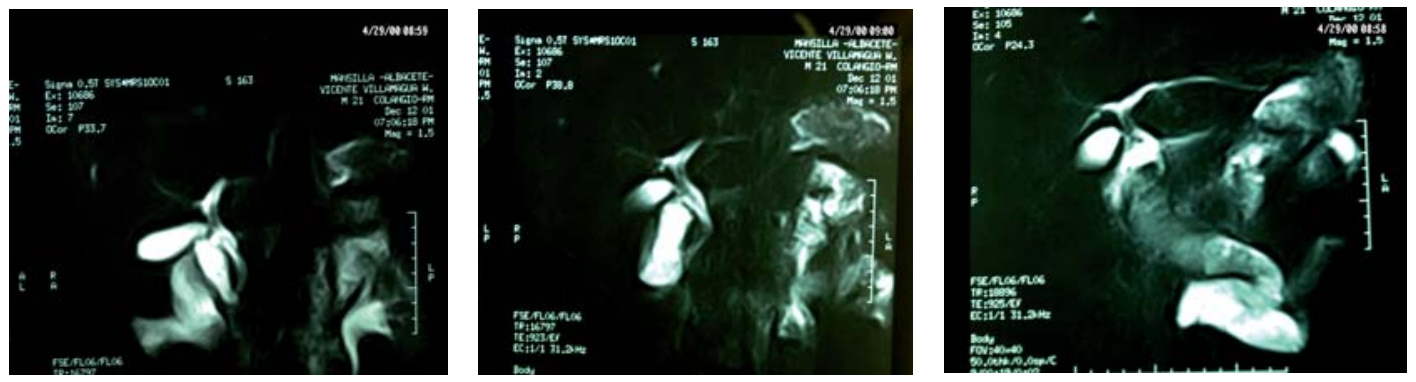

Figura 1. Imágenes de la colangio-resonancia.

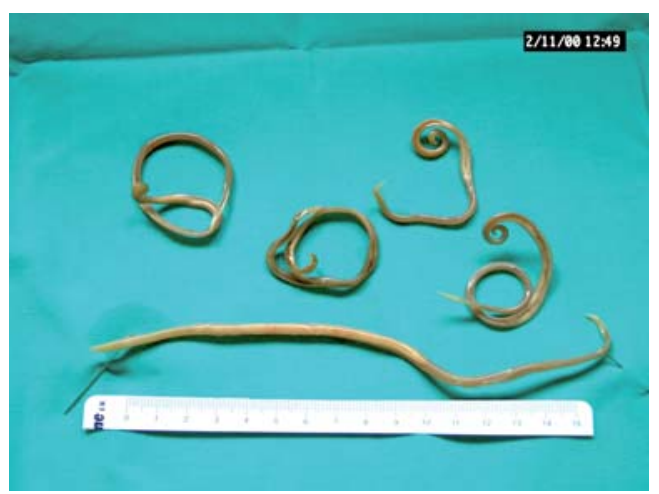

Figura 2. Áscaris lumbricoides. 